\title{
SPONTANEOUS REGENERATION OF THE LATERAL MALLEOLUS AFTER TRAUMATIC LOSS IN A THREE-YEAR-OLD BOY
}

\author{
A CASE REPORT WITH SEVEN-YEAR FOLLOW-UP
}

HUI-WAN PARK, HYON-JEONG KIM， BYEONG-MUN PARK

From Youngdong Severence Hospital, Seoul, Korea

We describe a three-year-old boy who had spontaneous regeneration of the entire lateral malleolus after injury, including the epiphysis, physis and metaphysis.

J Bone Joint Surg [Br] 1997;79-B:66-7.

Received 8 July 1996; Accepted 7 October 1996

In children with bone injuries the high osteogenic potential can lead to spontaneous regeneration of significant bone loss. Previous reports have been limited to the diaphysis or metaphysis of long bones. ${ }^{1-4}$ We describe an exceptional case of spontaneous regeneration of the whole lateral malleolus, including the epiphysis, physis, and metaphysis in a three-year-old boy after injury.

\section{CASE REPORT}

A three-year-old boy sustained an open crushing injury of his left ankle and foot after being struck by a car. He lost the whole of his left lateral malleolus, a segment about $2 \mathrm{~cm}$ in length including the secondary ossification centre of the distal fibula, with extensive soft tissue damage (Fig. 1). Associated injuries included loss of toe extensors, open fractures of the calcaneus and talus with partial bone loss, and a closed fracture of the tibial shaft. After irrigation and debridement of the wound the leg was immobilised in a posterior plaster cast. Parenteral cephalosporin was given and daily wound dressings were used. Three weeks later the wound had granulated and the defect was covered with a split-thickness skin graft.

At six weeks, radiographs showed a small ossific nucleus in the distal fibula indicating regeneration of the secondary

H.-W. Park, MD, Professor of Orthopaedic Surgery

H.-J. Kim, MD, Orthopaedic Resident

B.-M. Park, MD, Professor of Orthopaedic Surgery

Yonsei University College of Medicine, Youngdong Severance Hospital, 146-92 Dogok-Dong Kangnam-Gu, Seoul, South Korea

Correspondence should be sent to Dr H.-W. Park.

(c)1997 British Editorial Society of Bone and Joint Surgery 0301-620X/97/17074\$2.00
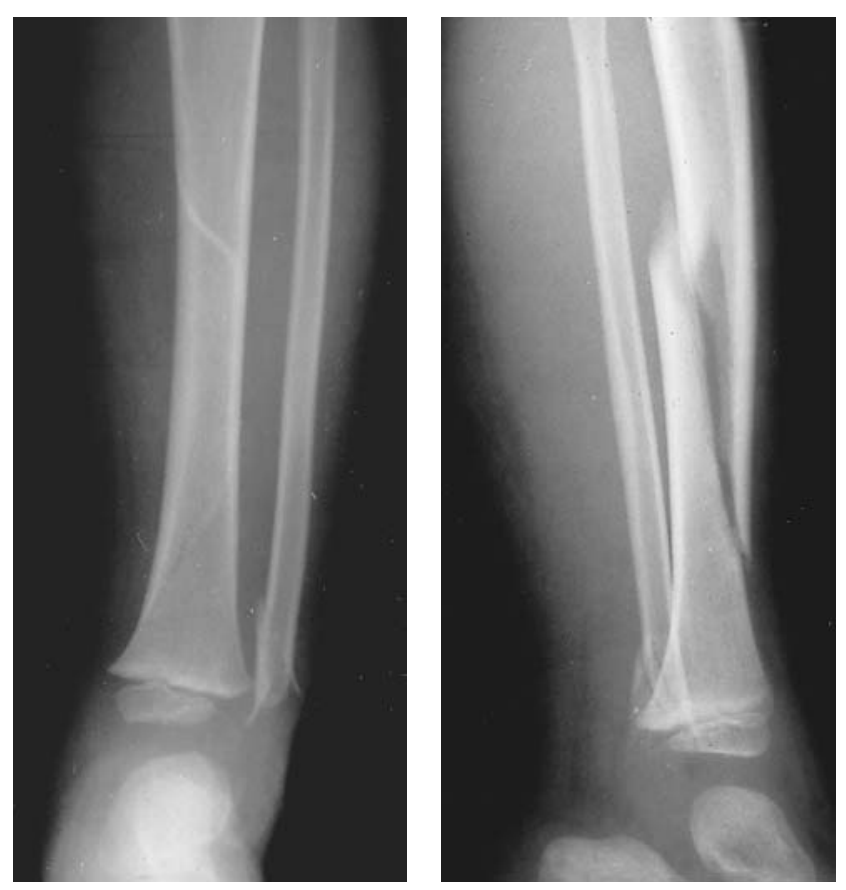

Fig. 1

Radiographs show complete loss of the left lateral malleolus. Associated injuries were a closed spiral fracture of the tibial shaft and open fractures of the calcaneus and talus with some bone loss.

ossification centre (Fig. 2a). Four months later, regeneration of the lateral malleolus had accelerated with an enlarged ossific nucleus (Fig. 2b).

Six years after the injury we resected the thick contracted scars over the lateral aspect of left ankle to correct an abnormally valgus position and covered the defect with a free vascularised parascapular flap. At seven-year followup, the lateral malleolus was seen to have regenerated and had an epiphysis, physis, and metaphysis. Although smaller and thinner than the normal contralateral malleolus (Fig. 2c), the valgus stress film showed that the angle between the articular surfaces of the distal tibia and the talar dome was $7^{\circ}$ (right side $3^{\circ}$ ), indicating acceptable stability of the ankle (Fig. 3). 


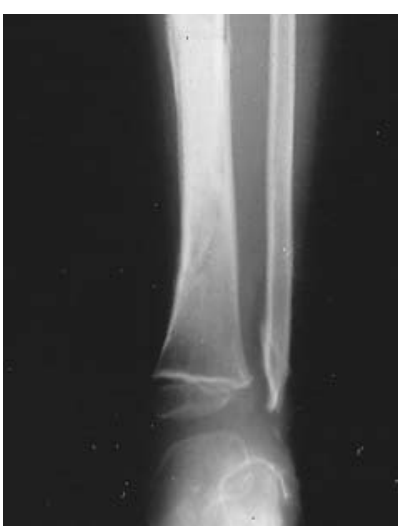

Fig. 2a

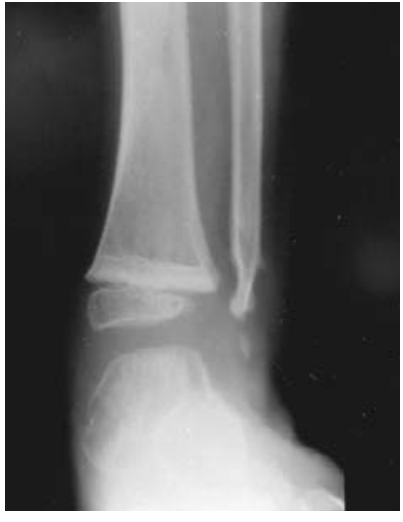

Fig. 2b

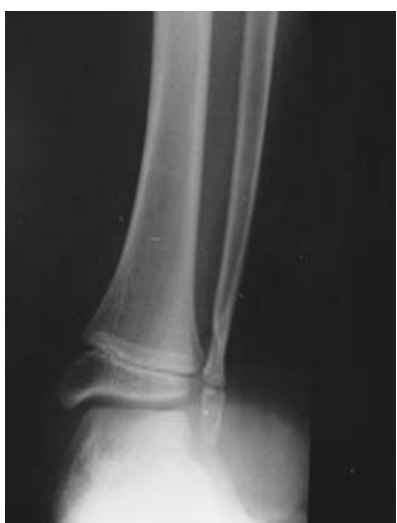

Fig. 2c

Six weeks after fracture a small ossific nucleus appeared in the distal fibula (a) and at four months more regeneration of the lateral malleolus was visible $(b, c)$. At seven years the left lateral malleolus had regenerated, and showed distinct epiphysis, physis, and metaphysis; though its thickness was reduced (c).

\section{DISCUSSION}

One of the characteristics of a child's bone is its greater capacity for osteogenesis. Much of the bone is still cartilaginous with a thick, strong periosteum which strips rather than tears when a fracture occurs. Previous reports have described spontaneous regeneration of large segmental losses of the diaphysis in long bones, but this regeneration has been limited to the diaphysis or the metaphysis. ${ }^{1-4}$ It has been suggested that the remaining periosteal tube has a significant role in the repair of defects in the diaphysis.

Our patient showed regeneration of the epiphysis and physis including part of the metaphysis of the lateral malleolus, which to our knowledge has not previously been reported. The regeneration probably began in the partially intact epiphyseal cartilaginous tissue surrounding the secondary ossification centre of the distal fibula and also in the periosteum on the medial side of the lateral malleolus, neither of which was visible on plain radiographs. In addition to osteogenic cells these tissues contain cartilaginous cells and pluripotential cells which can differentiate into osteogenic cells. The decreased thickness of the regenerated lateral malleolus is probably due to the loss of the perichondrial ring at the time of the injury, which impaired appositional bone growth.

No benefits in any form have been received or will be received from a commercial party related directly or indirectly to the subject of this article.

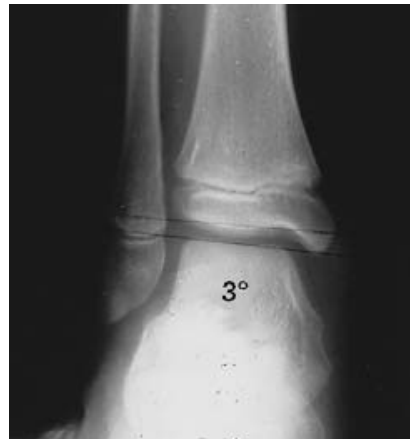

Fig. 3a

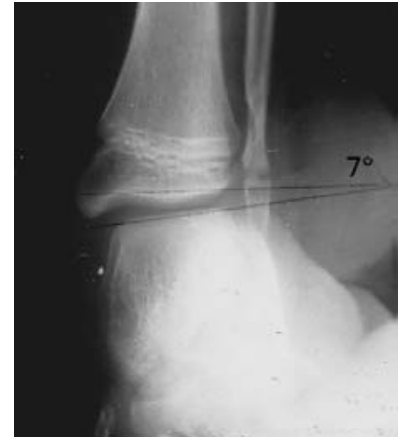

Fig. 3b
A valgus stress film made seven years after the accident showed a valgus angle of $7^{\circ}\left(\right.$ right side $3^{\circ}$ ) between the articular surfaces of the distal tibia and the talar dome.

\section{REFERENCES}

1. St Clair Strange FG. Union of fractures. Lancet 1963;I:305-7.

2. Bosworth DM, Liebler WA, Nastasi AA, Hameda K. Resection of the tibial shaft for osteomyelitis in children: a thirty-two year followup study. J Bone Joint Surg [Am] 1966;48-A:1328-39.

3. Varma BP, Srivastava TP. Successful regeneration of large extruded diaphyseal segments of the radius: report of two cases. J Bone Joint Surg [Am] 1979;61-A:290-2.

4. Mesko JW, DeRosa GP, Lindseth RE. Segmental femur loss in children. J Pediatr Orthop 1985;5:471-4. 